\title{
HUBUNGAN ANTARA ADVERSITY QUOTIENT (AQ) DENGAN PROKRASTINASI AKADEMIK SISWA KELAS X SMA NEGERI 5 KOTA BENGKULU
}

\author{
Umi Apriliani, Wasidi, Afifatus Sholihah \\ Prodi Bimbingan dan Konseling Fakultas Keguruan dan Ilmu Pendidikan \\ Universitas Bengkulu \\ umiapriliani1720@gmail.com, wasidirma@unib.ac.id, asholihah@unib.ac.id
}

\begin{abstract}
ABSTRAK
Penelitian ini bertujuan untuk mengetahui hubungan antara Adversity Quotient dengan prokrastinasi akademik siswa Kelas X di SMA Negeri 5 Kota Bengkulu. Sampel dalam penelitian ini adalah siswa SMA Negeri 5 Kota Bengkulu Kelas X MIPA 2 dan X MIPA 5 yang berjumlah 61 orang. Metode yang digunakan dalam peneltian ini yaitu korelasi kuantitatif untuk melihat hubungan antara variabel bebas dengan variabel terikat. Teknik pengumpulan data yang digunakan yaitu kuisioner dalam bentuk skala Likert. Teknik analisis data digunakan teknik korelasi product moment. Kesimpulan hasil terdapat hubungan negatif yang signifikan antara Adversity Quotient dengan prokrastinasi akademik siswa. Hal ini dapat diketahui dari nilai koefisien korelasi $r_{x y}=-0.681$ dan taraf signifikansi $0,000<0,05$. Hal ini menunjukkan bahwa terdapat hubungan negatif antara Adversity Quotient dengan prokrastinasi akademik, artinya semakin tinggi Adversity Quotient semakin rendah prokrastinasi akademik, dan sebaliknya.
\end{abstract}

Kata kunci: adversity quotient, prokrastinasi akademik

\section{THE CORRELATION BETWEEN ADVERSITY QUOTIENT (AQ) ANDACADEMIC PROCRASTINATION STUDENT AT SMA NEGERI 5 KOTA BENGKULU}

\begin{abstract}
The aim of this research is to know whether there is any correlation between adversity quotient and academic procrastination students of grade $X$ at SMA Negeri 5 Kota Bengkulu. The sample of this research take 61 students, and the method of the research usesquantitative correlation to know the correation between independent variable and dependent variable. The technique of collecting data used quistioner in Likert scale form. The technique of analyzing data used technique correlation product moment. Conclusion of research result there is any significant negative correlation between adversity quotient and academic procrastination student. It could be seen from the result of correlation cooficient that rxy $=-0.681$ and significant level is $0,000<0,05$. This revealed that there was negative correlation between adversity quotient and academic procrastination, it means the higher adversity quotient so lower academic procrastination, and the other way.
\end{abstract}

Keywords: academic procrastination, adversity quotient 


\section{Pendahuluan}

Hakikat manusia sebagai makhluk ciptaan Tuhan yang paling sempurna dan paling tinggi derajatnya mendorong manusia untuk dapat terus mengembangkan potensi yang dimilikinya. Salah satunya dengan cara menempuh pendidikan formal di sekolah. Hal ini sesuai dan telah tercantum dalam tujuan pendidikan nasional yaitu untuk mengembangkan kemampuan, serta meningkatkan mutu kehidupan dan martabat manusia Indonesia (dalam Sani dkk. 2015 : 37).

Belajar adalah tugas utama dari setiap siswa, namun tidak semua siswa mampu melakukan kegiatan belajar dengan baik. Banyak hal yang dapat menghambat kegiatan belajar siswa salah satunya seperti pengelolaan waktu belajar. Pengelolaan waktu belajar yang kurang baik dapat menyebabkan tertundanya penyelesaian tugas-tugas akademik yang dilakukan.

Mengerjakan tugas-tugas akademik merupakan suatu keharusan bagi setiap siswa. Agar mendapatkan hasil yang maksimal, setiap siswa harus mampu mengatur waktu belajarnya dengan baik. Menurut Djamarah, banyak mahasiswa dan pelajar mengeluh karena tidak dapat membagi waktunya dengan baik, kapan harus memulai dan mengerjakan sesuatu (dalam Sultoni, 2013). Dengan demikian, mereka akan mengulur waktu dan menunda penyelesaian tugas yang diberikan.

Perilaku untuk terus menerus menunda suatu pekerjaan sering disebut dengan prokrastinasi. Orang yang melakukan prokrastinasi sering disebut dengan prokrastinator. Sedangkan penundaan yang dilakukan untuk menyelesaikan tugastugas sekolah disebut dengan prokrastinasi akademik.

Ferrari, dkk. (dalam Ghufron dan Risnawita, 2014 : 168-159) berpendapat bahwa ciri-ciri prokrastinasi akademik adalah penundaan untuk memulai maupun menyelesaikan kerja pada tugas yang dihadapi, keterlambatan dalam mengerjakan tugas, kesenjangan waktu antara rencana dan kinerja aktual dan melakukan aktivitas lain yang lebih menyenangkan dari pada melakukan tugas yang harus dikerjakan. Agar dapat menyelesaikan tugas-tugas yang di berikan dengan tepat waktu, setiap siswa sebaiknya memiliki pengelolaan waktu yang baik.

Menurut penelitian yang telah dilakukan oleh Munawaroh dkk. (2017), di SMP Muhammadiyah 9 Yogyakarta menunjukan bahwa dari keseluruhan 
responden, sebanyak $17.2 \%$ pelajar memiliki prokrastinasi akademik yang tinggi, 77.1\% memiliki prokrastinasi akademik yang sedang, sedangkan 5.7\% memiliki prokrastinasi akademik yang rendah. Ini menunjukan bahwa masih sangat banyak siswa yang melakukan penundaan (prokrastinasi) dalam belajarnya.

Menurut penjelasan data di atas, peneliti juga menemukan beberapa indikasi fenomena prokrastinasi yang terjadi pada sebagian siswa yang terbukti mengalami dan sebagian juga tidak mengalami perilaku prokrastinasi yang terjadi di SMA Negeri 5 Kota Bengkulu. Perilaku prokrastinasi yang terjadi tersebut diantaranya sering mengalami hambatan-hambatan untuk berprestasi terutama untuk menyelesaikan tugas-tugas yang diberikan. Hambatan-hambatan itu seperti semangat belajar yang rendah, pengaruh teman yang kurang baik, penyesuaian yang kurang baik terhadap sistem sekolah, sering mengulur waktu, lebih suka melakukan hal-hal yang membuatnya senang sehingga tugas-tugas sering terbengkalai, serta lebih memilih mengerjakan tugas jika sudah hampir deadline.

Berdasarkan hasil obsevasi yang telah dilakukan oleh peneliti pada bulan Agustus hingga November (tiga bulan) di SMA Negeri 5 Kota Bengkulu mendapatkan hasil bahwa sebagian siswa khususnya kelas $\mathrm{X}$ (sepuluh) sering menunjukan perilaku prokrastinasi seperti, tidak segera mengerjakan tugas yang diberikan oleh guru, mereka lebih memilih bermain gaget terlebih dahulu dibanding segera menyelesaikan tugas, terkadang ada siswa yang tertidur di dalam kelas, mengerjakan tugas rumah (PR) yang akan dikumpulkan di kelas, serta sering meminta izin keluar kelas dengan alasan yang terkadang tidak terlalu penting. Peneliti juga telah melakukan wawancara dengan guru bimbingan dan konseling di SMA tersebut dan memperoleh data bahwa siswa kelas X (sepuluh) memiliki semangat belajar yang rendah, masih kurang mampu menyesuaikan diri terhadap sistem sekolah seperti sering datang terlambat, serta nilai-nilai akademiknya juga perlu ditingkatkan.

Setiap hambatan dan kesulitan yang ada tentunya harus segera dihadapi dan diatasi. Kemampuan individu dalam menghadapi hambatan dan mengubahnya menjadi peluang ini disebut dengan Adversity Quotient (AQ). Setiap individu memiliki derajat Adversity Quotient (AQ) yang berbeda-beda. Semakin tinggi 
tingkat Adversity Quotient (AQ) seseorang, maka semakin besar kemungkinan orang tersebut untuk bersikap optimis, dan inovatif dalam menghadapi hambatanhambatan. Sebaliknya, semakin rendah tingkat Adversity Quotient ( $A Q)$ seseorang semakin mudah seseorang untuk menyerah, menghindari tantangan dan mengalami stress (Stoltz, 2000 : 9-25).

Berdasarkan uraian sebelumnya maka penelitian ini ingin membuktikan “adakah hubungan antara Adversity Quotient ( $A Q)$ dengan prokrastinasi akademik pada siswa kelas X SMA Negeri 5 Kota Bengkulu”. Penelitian ini bertujuan untuk mengetahui "adakah hubungan yang negatif antara Adversity Quotient (AQ) dengan prokrastinasi akademik pada siswa kelas X SMA Negeri 5 Kota Bengkulu.

\section{Metode Penelitian}

Penelitian ini adalah penelitian kuantitatif dengan jenis penelitian korelasi yang dilanjutkan dengan menghitung besarnya hubungan antara variabel bebas terhadap variabel terikat. Variabel yang dihubungkan dalam penelitian ini adalah Adversity Quotient sebagai variabel (X) dan Prokrastinasi Akademik sebagai variabel (Y). Penelitian dilakukan di Kelas X SMA Negeri 5 Kota Bengkulu. Kegiatan penelitian ini di lakukan selama satu bulan dari tanggal 5 maret 2018 sampai dengan 31 Maret 2018. Adapun sampel dalam penelitian ini adalah siswa kelas X MIPA 2 dan X MIPA 5 SMA Negeri 5 Kota Bengkulu yang berjumlah 61 orang.

Untuk mengumpulkan dan mengungkapkan data mengenai hubungan antara Adversity Quotient dan prokrastinasi akademik, maka teknik pengumpulan data yang digunakan adalah dengan mengunakan instrumen berupa angket/kuesioner. Metode angket ini digunakan untuk mengukur tingkat prokrastinasi akademik dan derajat Adversity Quotient. Metode angket dengan modifikasi dari skala Likert digunakan mengingat variabel independen yang disertakan dalam penelitian ini dapat diungkapkan menggunakan skala. Skala respon yang digunakan dalam penelitian ini berjumlah 4 skala yaitu, Sangat Setuju (SS), Setuju (S), Tidak Setuju (TS), dan Sangat Tidak Setuju (STS). 
Untuk memperoleh data dan mengungkap fakta mengenai prokrastinasi akademik, digunakan angket yang mengacu pada teori yang dikemukakan oleh Ferrari (1995). Angket ini bertujuan untuk mengukur tingkat perilaku prokrastinasi akademik berdasarkan pada ciri-ciri seseorang melakukan perilaku prokrastinasi. Ciri-ciri tersebut adalah penundaan untuk memulai dan menyelesaikan tugas, keterlambatan dalam mengerjakan tugas, kesenjangan waktu antara rencana dan kinerja aktual, serta melakukan aktivitas yang lebih menyenangkan.

Pada variabel Adversity Quotient digunakan angket yang dikembangkan dengan mengacu pada teori yang dikemukakan oleh Stoltz (2000). Angket ini bertujuan untuk mengukur tingkat Adversity Quotient berdasarkan pada aspekaspek Adversity Quotient itu sendiri. Aspek-aspek itu seperti control atau kendali, origin dan ownership atau asal usul dan pengakuan, reach atau jangkauan, dan endurance atau daya tahan.

Pada penelitian ini, validitas yang perlu dilakukan adalah mengenai validitas isi. Validitas isi merupakan validitas yang diestimasi lewat pengujian terhadap kelayakan atau relevensi isi tes melalui analisis rasional oleh panel yang berkompeten atau melalui expert judgement (penilaian ahli). Validitas isi ini dilakukan untuk memastikan apakah isi kuesioner sudah sesuai dan relevan dengan tujuan studi/penelitian (dalam Suryani \& Hendryadi, 2015 : 145). Setelah dilakukan uji validitas oleh para ahli, dilakukan uji daya beda kepada 33 siswa kelas X MIPA 5 SMA Negeri 5 Kota Bengkulu, dan didapatkan sebanyak 18 aitem valid untuk mengukur tingkat Adversity Quotient (AQ) dan tingkat prokrastinasi akademik siswa. Butir yang valid diuji reliabilitasnya dengan menggunakan teknik Cronbach's Alpha. Angka reliabilitasnya pada angket Adversity Quotient ( $A Q$ ) sebesar 0.845, dan pada angket prokrastinasi akademik sebesar 0.878 , ini berarti angka reliabilitas dari kedua angket tersebut dapat dikatakan baik.

Teknik analisis data yang digunakan untuk menguji hipotesis ini adalah analisis korelasi sederhana Person Product Moment yang digunakan untuk 
mengetahui hubungan antara variabel adversity quotient $(\mathrm{X})$ dengan prokrastinasi $\operatorname{akademik}(\mathrm{Y})$.

\section{Hasil dan Pembahasan}

\section{Tabel 1.1}

Jumlah Skor Setiap Aspek Adversity Quotient (AQ)

\begin{tabular}{cccccc}
\hline & Control & Origin & Ownership & Reach & Endurance \\
\hline N & 61 & 61 & 61 & 61 & 61 \\
\hline Jumlah & 733 & 339 & 900 & 293 & 861 \\
\hline
\end{tabular}

Dari Tabel di atas dapat diketahui skor pada indikator 1 sebesar 733, skor pada indikator 2 sebesar 339, skor pada indikator 3 sebesar 900, skor pada indikator 4 sebesar 293, dan skor pada indikator 5 sebesar 861. Jadi Indikator Adversity Quotient yang tertinggi adalah indikator ownership (pengakuan diri) dengan skor 900, dan indikator terendah adalah indikator jangkuan (reach) dengan skor 293. Agar skor pada penelitian ini dapat memberikan gambaran yang jelas, maka dibuat tiga ketegori kelompok tingkat Adversity Quotient (AQ) subjek penelitian sebagai berikut:

Tabel 1.2

Kategori Tingkat Adversity Quotient

\begin{tabular}{cccc}
\hline No & Kategori & Frekuensi & Presentase \\
\hline 1. & Tinggi & 12 & $19.67 \%$ \\
\hline 2. & Sedang & 40 & $65.57 \%$ \\
\hline 3. & Rendah & 9 & $14.75 \%$ \\
\hline \multicolumn{2}{c}{ Jumlah } & $\mathbf{6 1}$ & $\mathbf{1 0 0 \%}$ \\
\hline
\end{tabular}

Berdasarkan Tabel 2.2, diperoleh bahwa dari 61 responden yang berpartisipasi terdapat 12 atau $19.67 \%$ siswa yang memiliki tingkat Adversity Quotient yang tinggi, 40 atau $65.57 \%$ siswa memiliki tingkat Adversity Quotient yang sedang, dan 9 atau $14.75 \%$ siswa memiliki tingkat Adversity Quotient yang rendah. Sehingga dari hasil tersebut, dapat diketahui bahwa tingkat Adversity Quotient siswa kelas X di SMA Negeri 5 berada pada kategori sedang. 
Data Prokrastinasi Akademik terdiri atas 18 aitem pernyataan dari 4 aspek dapat dilihat pada tabel berikut:

Tabel 1.3

Jumlah Skor Setiap Aspek Prokrastinasi Akademik

\begin{tabular}{ccccc}
\hline & Indikator 1 & Indikator 2 & Indikator 3 & Indikator 4 \\
\hline $\mathrm{N}$ & 61 & 61 & 61 & 61 \\
\hline Jumlah & 793 & 582 & 428 & 805 \\
\hline
\end{tabular}

Dari Tabel 1.3, dapat diketahui skor pada aspek 1 sebesar 793, skor pada aspek 2 sebesar 582, skor pada aspek 3 sebesar 428, skor pada aspek 4 sebesar 805. Jadi aspek prokrastinasi akademik yang tertinggi adalah aspek melakukan aktivitas yang lebih menyenangkan dengan skor 805 dan aspek yang terendah adalah aspek kesenjangan waktu antara rencana dan kinerja aktual dengan skor 428.

Agar skor pada penelitian ini dapat memberikan gambaran yang jelas, maka dibuat tiga ketegori kelompok tingkat prokrastinasi akademik subjek penelitian sebagai berikut:

Tabel 1.4

Kategori Tingkat Prokrastinasi Akademik

\begin{tabular}{cccc}
\hline No & Kategori & Frekuensi & Presentase \\
\hline 1. & Tinggi & 11 & $18.03 \%$ \\
\hline 2. & Sedang & 41 & $67.21 \%$ \\
\hline 3. & Rendah & 9 & $14.75 \%$ \\
\hline & Jumlah & $\mathbf{6 1}$ & $\mathbf{1 0 0 \%}$ \\
\hline
\end{tabular}

Berdasarkan Tabel 1.4, diperoleh bahwa dari 61 responden yang berpartisipasi terdapat 11 atau $18.03 \%$ siswa yang memiliki tingkat Prokrastinasi Akdemik yang tinggi, 41 atau $67.21 \%$ siswa memiliki tingkat Prokrastinasi Akademik yang sedang, dan 9 atau $14.75 \%$ siswa memiliki tingkat Prokrastinasi Akdemik yang rendah. Sehingga dari hasil tersebut, dapat diketahui bahwa tingkat Prokrastinasi Akademik siswa kelas X di SMA Negeri 5 berada pada kategori sedang. 
Dari hasil uji normalitas menggunakan teknik Statistic Non Parametrik One Simple Kolmogorov-Smirnov menunjukkan hasil pengujian normalitas data Adversity Quotient $(A Q)$ dan Prokrastinasi Akademik dengan SPSS Statistik Ver. 17. Berdasarkan uji Kolmogorov-Smirnov dengan memperhatikan bilangan pada kolom signifikasi (Sig) yaitu 0.316 dan 0.819 lebih besar dari 0.05 (0.316>0.05 dan 0.819>0.05). Berdasarkan hal tersebut dapat disimpulkan bahwa untuk variabel Adversity Quotient (AQ)dan Prokrastinasi Akademik berdistribusi normal pada taraf signifikasi 0,05 , maka semua variabel secara statistik telah berdistribusi secara normal dan layak digunakan sebagai data penelitian.

Uji hipotesis bertujuan untuk mengetahui jika data sesuai dengan hipotesis dan tujuan penelitian yaitu untuk mengetahui ada atau tidaknya hubungan antara Adversity Quotient (AQ) dan Prokrastinasi Akademik siswa kelas X SMA Negeri 5 Kota Bengkulu. Berdasarkan correlation bivariate analysis antara adversity quotient (X) dengan prokrastinasi akademik (Y) dengan menggunakan bantuan program SPSS Statistick Ver. 17, maka dapat diperoleh hasil sebagai berikut:

Tabel 1.5

Hasil Uji Korelasi

\begin{tabular}{cccc}
\hline & & $\begin{array}{c}\text { Prokrastinasi } \\
\text { Akademik }\end{array}$ & $\begin{array}{c}\text { Adversity } \\
\text { Quotient }\end{array}$ \\
\hline Prokrastinasi & Pearson Correlation & 1 & $-0.681^{* *}$ \\
Akademik & Sig. (2-tailed) & & 0.000 \\
& $\mathrm{~N}$ & 61 & 61 \\
\hline \multirow{2}{*}{$\begin{array}{c}\text { Adversity } \\
\text { Quotient }\end{array}$} & Pearson Correlation & $-0.681^{* *}$ & 1 \\
\hline & Sig. (2-tailed) & 0.000 & \\
\hline$* *$ N Correlation is significant at the 0.01 level (2-tailed).
\end{tabular}

**. Correlation is significant at the 0.01 level (2-tailed).

Dari Tabel 1.5, menunjukan bahwa ada korelasi yang signifikan $\left(\mathrm{r}_{\mathrm{xy}}=\right.$ $0.0681 ;$ sig $=0.000<0.05)$ antara Adversity Quotient dan Prokrastinasi Akademik. Dapat dikatakan signifikan atau mempunyai hubungan apabila $\mathrm{r}$ hitung lebih besar dai $r$ tabel. Dengan taraf signifikansi 5\%, r hitung dari korelasi di atas memiliki nilai $\mathrm{r}_{\text {hit }}=-0.0681$ denga probabilitas 0.000 . Jika $\mathrm{p}<0.05$ maka $\mathrm{H}_{0}$ 
ditolak, sedangkan jika $\mathrm{p}=0.05$ maka $\mathrm{H}_{\mathrm{a}}$ diterima. Hasil dari probabilitas menunjukan angka 0.000 ini berarti probabilitas kurang dari 0.05 maka $\mathrm{H}_{0}$ ditolak dan $\mathrm{H}_{\mathrm{a}}$ diterima. Artinya, terdapat hubungan (korelasi) yang signifikan antara Adversity Quotient dengan Prokrastinasi Akademik siswa Kelas X di SMA Negeri 5 Kota Bengkulu.

Berdasarkan analisis di atas, dapat dilihat bahwa terdapat hubungan negatif yang sangat signifikan antara Adversity Quotient dan Prokrastinasi Akademik. Ini ditunjukan dengan $r_{x y}(-0.681)$. Ini memiliki arti bahwa semakin tinggi tingkat Advrsity Quotient siswa kelas X di SMA Negeri 5 Kota Bengkulu, maka akan semakin rendah prokrastinasi akademiknya. Sebaliknya, jika semakin rendah tingkat Adversity quotient siswa kelas X SMA Negeri 5 Kota Bengkulu maka akan semakin tinggi prokrastinasi akademik yang dilakukannya.

Penundaan tugas dikalangan siswa merupakan fenomena yang biasa dan sudah sering kali terjadi. Namun ini dapat menimbulkan dampak yang besar bagi proses belajar siswa itu sendiri. Penundaan tugas yang dilakukan secara berulangulang dan terus-menerus dapat menghasilkan akibat-akibat lain yang lebih jauh, seperti misalnya seseorang yang memiliki kecenderungan untuk menunda akan lebih lambat dalam menyelesaikan tugas yang menyebabkan ia akan tergesa-gesa sehingga hasil yang diperoleh tidak maksimal. Selain itu hal ini akan berdampak pada keadaan emosional seorang prokrastinator. Akan adanya kerisauan emosional yang timbul ketika seseorang melakukan prokrastinasi, mereka akan memiliki perasaan cemas, perasaan bersalah, marah, dan panik.

Menurut Millgram, Mey-Tal \& Levinson (dalam Burhani, 2016), seorang prokrastinator sebenanya memiliki persepsi bahwa suatu tugas sangat penting untuk dikerjakan. Mereka mengetahui bahwa penyelesaian tugas merupakan hal yang penting, tetapi cenderung tidak segera diselesaikan dan bahkan mengerjakan tugas lain yang tidak penting. Solomon dan Rothblum (dalam Surijah dan Tjundjing, 2007) juga menjelaskan bahwa prokrastinasi adalah penundaan dalam mulai mengerjakan atau menyelesaikan tugas yang disengaja. Ini berarti bahwa 
perilaku prokrastinasi adalah perilaku yang disengaja, maksudnya faktor-faktor yang menunda penyelesaian tugas berasal dari keputusandirinya sendiri.

Menurut Sultoni (2013) fenomena penundaan tugas yang dialami siswa di sekolah juga disebabkan oleh kurangnya kesadaran siswa dalam memandang dan mengolah masalah dengan menggunakan potensi dirinya secara positif maupun negatif. Jika seseorang memiliki kesadaran yang tinggi dalam memandang dan mengolah masalah, ia akan bersikap kreatif dan inovatif dalam menyelesaikan masalah tersebut. Sebaliknya, seseorang yang memiliki kesadaran yang kurang dalam memandang dan mengolah masalah, ia akan mudah putus asa dan menyerah. Begitu juga dengan perilaku menunda, seseorang yang kurang mampu memandang dan mengolah masalah dengan baik akan mengalami hambatan dalam belajarnya. Ia akan mudah menyerah dalam mengerjakan tugas, ia menganggap bahwa suatu tugas itu sulit untuk dikerjakan sehingga ia akan mengulur waktu belajarnya.

Setiap hambatan dan kesulitan yang ada tentunya harus segera dihadapi dan diatasi. Kemampuan individu dalam menghadapi hambatan dan mengubahnya menjadi peluang ini disebut dengan Adversity Quotient (AQ). Setiap individu memiliki derajat Adversity Quotient (AQ) yang berbeda-beda. Ada yang tinggi, sedang ataupun rendah.

Semakin tinggi tingkat Adversity Quotient (AQ) seseorang, maka semakin besar kemungkinan orang tersebut untuk bersikap optimis, dan inovatif dalam menghadapi hambatan-hambatan. Seperti halnya seseorang yang melakukan prokrastinasi dengan menganggap bahwa suatu tugas itu sulit untuk dikerjakan, namun karena memiliki tingkat Adversity Quotient (AQ) yang tinggi ia akan memiliki motivasi yang kuat dan ketekunan yang tinggi untuk menyelesaiakn tugas-tugas tersebut.Sebaliknya, semakin rendah tingkat Adversity Quotient ( $A Q)$ seseorang semakin mudah seseorang untuk menyerah, menghindari tantangan dan mengalami stress (Stoltz, 2000 : 9-25).

Dari uraian di atas, menunjukan bahwa Adversity Quotient (AQ) merupakan faktor yang sangat diperlukan untuk individu dalam memahami dan mengolah masalah yang dialaminya, sehingga dapat dilihat bahwa semakin tinggi tingkat 
Advrsity Quotient (AQ)siswa, maka akan semakin rendah prokrastinasi akademiknya. Sebaliknya, jika semakin rendah tingkat Adversity quotient $(A Q)$ siswa maka akan semakin tinggi prokrastinasi akademik yang dilakukannya.

\section{Kesimpulan}

Berdasarkan hasil analisis korelasi yang telah dilakukan, didapatkan hasil $\mathbf{r}_{\mathrm{xy}}$ sebesar 0.681 dengan $\mathrm{p}=0.000(\mathrm{p}<0.05)$ yang berarti hipotesus diterima, maka terdapat hubungan negatif yang signifikan antara Adversity Quotient $(A Q)$ dengan Prokrastinasi Akademik siswa kelas X SMA Negeri 5 Kota Bengkulu. Artinya, semakin tinggi tingkat Adversity Quotient (AQ) siswa, maka akan semakin rendah tingkat prokrastinasi akademik yang dilakukannya, demikian sebaliknya semakin rendah tingkat Adversity Quotient $(A Q)$ seorang siswa, maka akan semakin tinggi tingkat prokrastinasi akademiknya.

Dari hasil penelitian ini, diharapkan dapat menambah pengetahuan bagi guru BK di sekolah untuk memberikan layanan bimbingan dan konseling yang tepat bagi setiap siswa untuk terus meningkatkan dan mengembangkan kecerdasannya dalam menyelesaikan masalah (Adversity Quotient). Sehingga tindakan prokrastinasi akademik siswa dapat terminimalisir guna terciptanya sumber daya manusia yang optimis dan berkualitas. Bagi penelitian selanjutnya, diharapkan dapat mempertimbangkan faktor lain yang dapat mempengaruhi tingkat Adversity Quotient seseorang maupun perilaku prokrastinasi.

\section{Daftar Pustaka}

Burhani, I.I. (2016). Pemaknaan Prokrastinasi Akademik Pada Mahasiswa Semester Akhir Di Universitas Muhammadiyah Surakarta. Skripsi. http://eprints.ums.ac.id, diunduh 13 Januari 2018.

Gufron, N dan Rini, R. (2014). Teori-teori Psikologi. Jogjakarta: Ar-ruzz Media.

Munawaroh, L.M, Said, A, dan Wahyu N.E.S. (2017). Tingkat Prokrastinasi Akademik Siswa Sekolah Menengah Pertama Muhammadiyah 9 Yogyakarta. Jurnal Kajian Bimbingan Konseling, 2 (1), 26-31.

Sani, A.R, Isda, P, dan Anies, M. (2015). Penjaminan Mutu Sekolah. Jakarta : Bumi Aksara. 
Stoltz, G.P. (2000). Adversity Quotient (Mengubah Hambatan Menjadi Peluang). Jakarta : Gramedia Widiasarana.

Sultoni, M. (2013). Hubungan antara Adersity Quotient dengan Prokrastinasi Akademik pada Siswa Kelas VIII Tahun Ajaran 2013-2014 Di SMP Negeri 1 Lawang. Skripsi. http://etheses.uin-malang.ac.id/1706/, diunduh 27 Desember 2017.

Surijah, A.E, dan Tjundjing, S. (2007). Mahasiswa Versus Tugas: Prokrastinasi Akademik dan Conscientiousness. Anima Indonesia Psychological Journal, $22(4), 352-374$.

Suryani, dan Hendryadi. (2015). Metode Riset Kuantitatif. Jakarta: Prenadamedia. 